\title{
MOLLUSCAN RECOVERY FROM THE K-T EXTINCTION: THE REASSEMBLY OF PROVINCIAL BIOTAS
}

JABLONSKI, David, Dept. of Geophysical Sciences, University of Chicago, 5734 South Ellis Ave., Chicago, IL 60637, U.S.A.

The end-Cretaceous mass extinction was remarkably homogeneous among marine bivalves and gastropods: Jablonski and Raup (1995) found anomalous intensities only in tropical shallow-water carbonate faunas (and not in tropical terrigenous faunas, or among major lifehabit categories). The Paleocene recovery, however, shows striking variations in the evolutionary behavior of clades and ecological groups, and in the biogeographic fabric of provincial biotas as diversity recovers. Comparisons of the Paleocene history of the molluscan faunas of (a) the Gulf and Atlantic Coastal Plain of North America (as documented by T. Hansen and collaborators) with the patterns in correlative units in (b) western and central Europe, (c) Pakistan, and (d) Egypt, permits a preliminary analysis of recovery in four biogeographic provinces, two subtropical/temperate $(a+b)$ and two tropical $(c+d$, both of which are more preliminary datasets). Each province follows a unique trajectory in terms of shifting faunal dominants. Taxa and modes of life that remained in eclipse in North America (e.g. shallow infauna like arcoids and cardiids) are quicker to recover in Europe, although carditids are also abundant in the Danian of Pakistan and Egypt, and turritellids are most abundant and diverse in North America and Egypt. Europe has a diversification among lucinoidean bivalves not seen in the other three regions, but epifaunal taxa rebound more rapidly in the three regions other than North America.

During a recovery episode, any provincial fauna will have three components: local survivors, immigrant survivors (i.e. taxa absent from a region before the extinction but subsequently introduced), and newly evolved taxa. The Danian faunas of Europe, Pakistan and Egypt have remarkably similar proportions among the survivor categories at the genus level (45$55 \%$ local, $10-15 \%$ immigrants), and differ significantly ( $p<0.01$, binomial tests) from the North American survivors ( $28 \%$ local, $25 \%$ immigrants). The contrast is striking in light of the closer geographic and presumed climatic affinities of Europe and North America. Further, the biases of the respective fossil records of these regions go against the reported results. The North American Coastal Plain has the best-preserved and best-sampled Late Cretaceous fauna in the world, so that rare, local survivors are much more likely to be recognized here than in the other regions, which should lower perceived immigration rates relative to other areas. On the other hand, local extinction and rapid re-invasion by widespread genera could mask differences in extinction intensity among provinces--a potential bias testable using well-defined subclades.

The North American recovery pattern is anomalous relative to the other three: only North America shows transient bursts of "bloom taxa" and has such an even ratio of local survivors and immigrants. Potential explanations range from greater ecological disruption despite similar numerical losses (e.g. owing to specific positions of extinction-prone endemics within food webs) to greater proximity to the apparent K-T impact site. If post-extinction provinces differ in their roles as sources or sinks of surviving (and presumably new) taxa, this further underscores the macroevolutionary complexity of recovery patterns when examined biogeographically, and, if rules for these differences can be detected, has implications for restoration ecology in present-day biotas as well.

Hansen, T.A. 1988. Paleobiology 14: 37-51.

Hansen, T.A., et al. 1993. Paleobiology 19: 251-266.

Jablonski, D., and D.M. Raup, 1995. Science 268: 389-391. 